\title{
INFLUÊNCIA DA PREPARAÇÃO DE LICOR DE JAMBOLÃO (SYZYGIUM CUMINI LAM.) NO TEOR DE COMPOSTOS FENÓLICOS
}

\author{
Marcela Franca Libório ${ }^{1}$; Taís Silva de Oliveira Brandão ${ }^{2}$ \\ 1. Bolsista PIBIC/Fapesb, Graduando em Engenharia de Alimentos, Universidade Estadual de Feira de Santana, e-mail: \\ marcelaliborio27@gmail.com \\ 2. Orientador, Departamento de Tecnologia, Universidade Estadual de Feira de Santana, e-mail: tbrandao@uefs.br
}

PALAVRAS-CHAVE: Jambolão, Compostos Fenólicos, Licor.

\section{INTRODUÇÃO}

Syzygium cumini é uma árvore nativa da Índia conhecida popularmente por jambolão, jamelão, jambeiro e azeitona preta, pertencente à família Myrtaceae (Oliveira; Bruno; Meneghello, 2015). Suas partes comestíveis podem ser consideradas excelentes fontes de antioxidantes e podem ser incluídas no ranking das frutas com maior potencial nutracêutico (Brandão et al., 2011).

Dentre os compostos fitoquímicos com atividade antioxidante presentes no jambolão merecem destaque os compostos fenólicos. Os compostos fenólicos podem ser definidos como substâncias que possuem um anel aromático com um ou mais grupos de hidroxila e tem sido muito estudado devido sua influência na qualidade dos alimentos. Os compostos fenólicos se enquadram em diversas categorias, conforme o número de anéis aromáticos e os elementos estruturais que se ligam a esses anéis (Soares, 2015).

Praticamente não existem produtos derivados de jambolão no mercado brasileiro e volumes consideráveis da fruta são perdidos devido a natural perecibilidade. O jambolão apresenta consumo restrito à forma in natura e grande parte dos frutos se acumulam nas ruas em época da safra, sem que nenhum processo tecnológico comercial seja utilizado para aproveitá-las (Araújo, 2014).

Os licores são uma alternativa para o aproveitamento de frutas regionais, agregando valor e possibilitando a geração de renda para as famílias rurais (Vieira et al., 2010). Dessa forma, o presente trabalho teve como objetivo avaliar o conteúdo de compostos fenólicos e outros parâmetros nas infusões alcoólicas e licores de jambolão com diferentes tratamentos, para duas safras (2017 e 2018).

\section{MATERIAL E MÉTODOS OU METODOLOGIA (ou equivalente)}

Os frutos de jambolão (Syzygium Cumini Lam.) foram colhidos no campus da Universidade Estadual de Feira de Santana (UEFS) na Bahia, Brasil.

Baseado em Geocze (2007), o processo de elaboração do licor foi definido em uma maceração alcoólica simples e outra com tratamento térmico da fruta por $60^{\circ} \mathrm{C}$ por dez minutos, em aguardente a $18{ }^{\circ} \mathrm{GL}$. Os tempos de extração (infusão) foram pré-definidos em nove, 15, e 30 dias, totalizando seis tratamentos distintos. Para elaboração dos licores foi feita filtração das infusões e adicionado xarope de açúcar com $71^{\circ}$ Brix. Foram realizadas análises de acidez, pH, sólidos solúveis totais (SST), segundo o Instituto Adolfo Lutz (2008), e compostos fenólicos nas infusões e nos licores, além das análises de cor e turbidez nestes últimos. O teor de compostos fenólicos foi avaliado por meio do método espectrofotométrico Folin-Ciocalteu desenvolvido por Singleton \& Rossi, 1965), adaptado por Georgé (2005). O ácido gálico foi utilizado para fazer a curva padrão e o resultado foi expresso em miligramas 
de equivalentes de ácido gálico por 100 gramas de extrato (mg EAG $100 \mathrm{~g}^{-1}$ ). A análise de cor foi realizada utilizando o espectrofotômetro modelo Femto 600 Plus, para medida de absorbância nos comprimentos de onda de 420, 520 e $620 \mathrm{~nm}$ (Glories,1984), ao passo que para a turbidez, no mesmo instrumento, foi medida a transmitância no comprimento de onda de 660 nm (Reed; Hendrix; Hendrix, 1986).

\section{RESULTADOS E/OU DISCUSSÃO (ou Análise e discussão dos resultados)}

Para a fruta, obteve-se valores de $\mathrm{pH}$ de $3,49( \pm 0,01)$ e 4,79 $( \pm 0,01)$ e de sólidos solúveis totais de 13,00 $( \pm 0,01)$ e 15,9 $( \pm 0,01){ }^{\circ}$ Brix para as safras de 2017 e 2018, respectivamente. Observou-se a influência discreta do período de colheita das frutas no $\mathrm{pH}$ das infusões, já que em 2017 o pH médio, do início ao final do processo foi de 3,97 $( \pm 0,04)$ e, em 2018, foi 4,17 ( \pm 0,08). Essa variação discreta pode ser observada também em valores de sólidos solúveis totais entre as safras em que, para o ano de 2017 obteve-se os valores médios $11,35( \pm 0,40){ }^{\circ}$ Brix e 32,28 $( \pm 0,30){ }^{\circ}$ Brix e, para o ano de 2018, 12,15 $( \pm 0,15){ }^{\circ}$ Brix e $32,88( \pm 0,23){ }^{\circ}$ Brix, para as infusões e licores em 2017 e 2018, respectivamente. As infusões elaboradas sem e com o tratamento térmico da fruta apresentaram valor médio de acidez de $0,21( \pm 0,01) \mathrm{g} / 100 \mathrm{~mL}$, enquanto que para os licores teve-se $0,16( \pm 0,01)$ e $0,17( \pm$ $0,01) \mathrm{g} / 100 \mathrm{~mL}$ para os anos de 2017 e 2018 , respectivamente.

Obteve-se um conteúdo de compostos fenólicos totais na fruta de, aproximadamente, $690,19( \pm 0,02) \mathrm{mg}$ EAG $100 \mathrm{~g}^{-1}$ de extrato, para safra de 2017 e 664,04 $( \pm 0,03) \mathrm{mg}$ EAG $100 \mathrm{~g}^{-1}$ de extrato, para safra de 2018. Os resultados de quantificação dos compostos fenólicos nos extratos alcoólicos e nos licores seguem nas figuras 1 e 2, para produção das duas safras.

Sem tratamento térmico da fruta (Safra 2017)

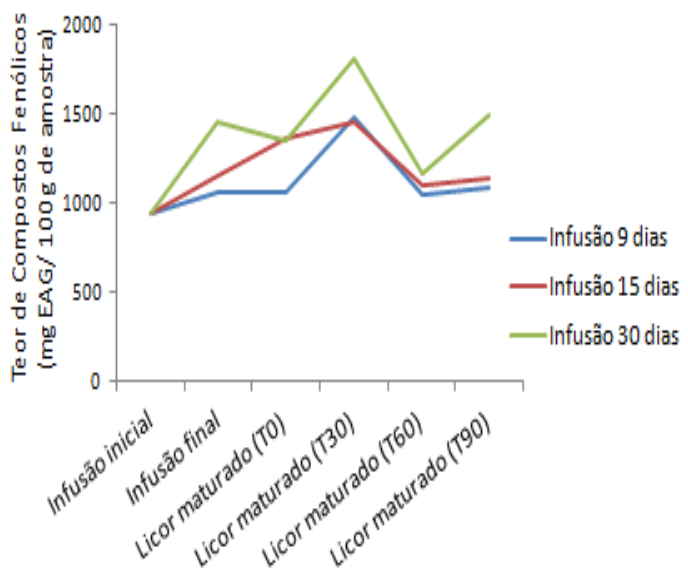

Com tratamento térmico da fruta (Safra 2017)

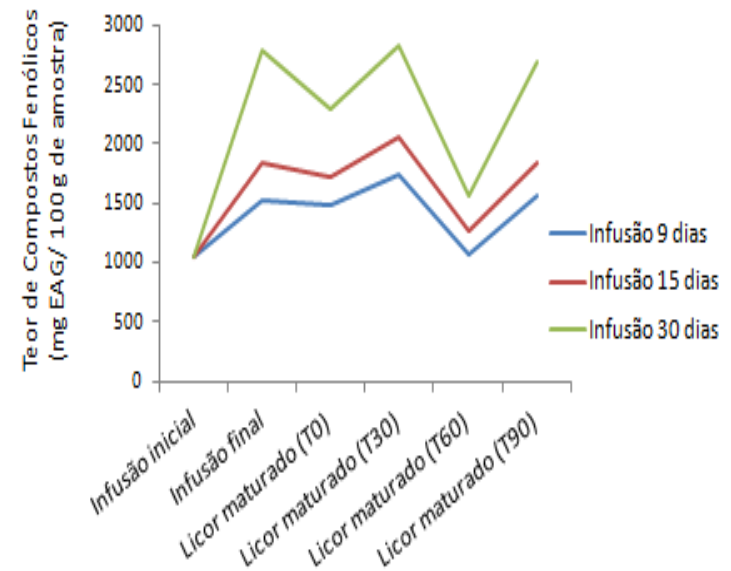

Figura 1: Conteúdo de compostos fenólicos nos extratos e licores sem aquecimento da fruta e com aquecimento da fruta, da safra de 2017. T0 - tempo zero; T30 - 30 dias de maturação; T60 - 60 dias de maturação; T90 - 90 dias de maturação. 

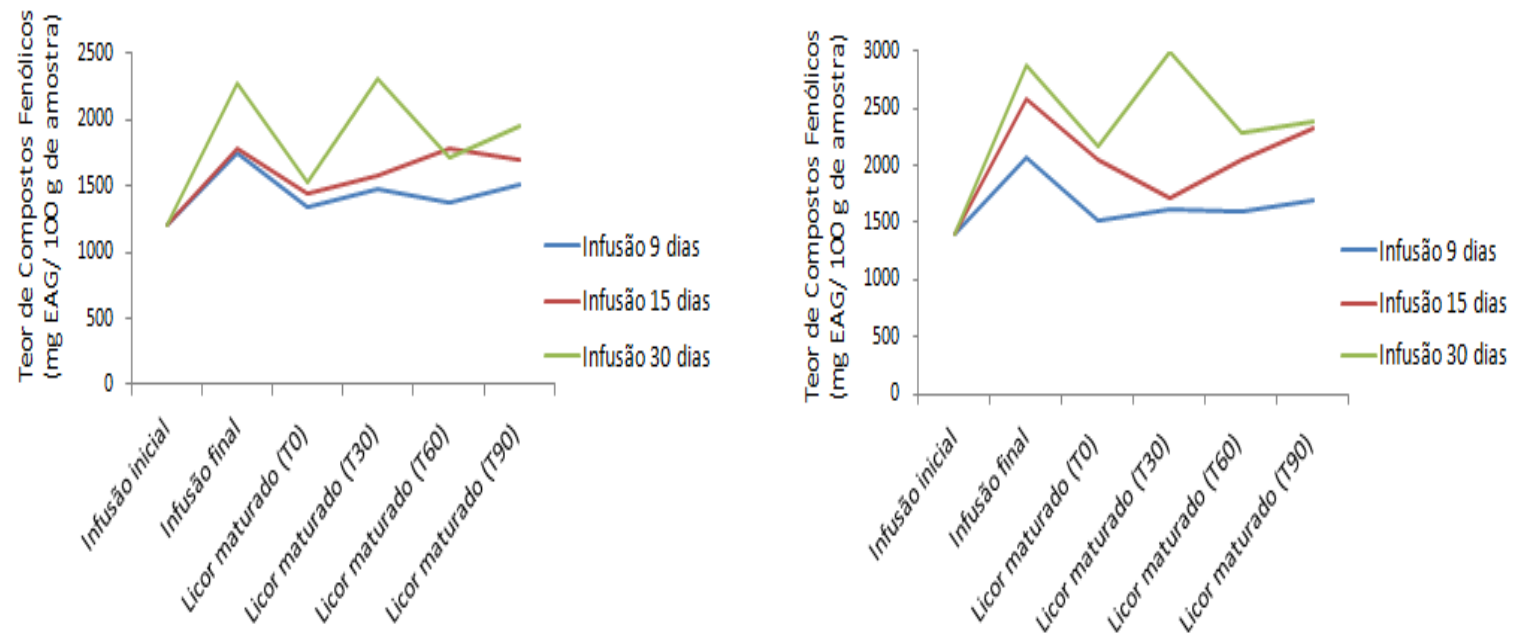

Figura 2: Conteúdo de compostos fenólicos nos extratos e licores sem aquecimento da fruta e com aquecimento da fruta, da safra de 2018. T0 - tempo zero; T30 - 30 dias de maturação; T60 - 60 dias de maturação; T90 - 90 dias de maturação.

Foi observado que quanto maior a quantidade de dias do contato da fruta com o aguardente, maior foi a extração de compostos fenólicos. Segundo Gaméz-Meza et al. (1999), a extração de compostos fenólicos é substancialmente influenciada pelo líquido extrator utilizado. É preciso considerar que a quantidade de compostos fenólicos presente nas sementes da fruta influencia no conteúdo de fenólicos total como verificado por Luzia \& Jorge (2009). Além disso, verificou-se maior extração nas infusões alcoólicas preparadas com frutas que passaram por tratamento térmico prévio. Estudos anteriores de Jeong et al. (2004a) e Jeong et al. (2004b), com sementes de gergelim, mostraram que o tratamento térmico promove a clivagem de ligações de compostos fenólicos, tornando-os solúveis. Esse maior teor de compostos fenólicos foi notório nos licores produzidos a partir dessas infusões. No entanto, variações discrepantes foram observadas e podem sem explicadas por fatores, como a baixa especificidade do método Folin-Ciocalteu na quantificação do conteúdo fenólico (Everette et al., 2010 apud Margraf et al., 2015). Algumas substâncias redutoras podem interferir na reação do método de Folin-Ciocalteu, como açúcares (Georgé et al., 2005).

Houve a predominância da cor amarela nos licores durante os envelhecimento, que pode ser explicada pela degradação das antocianinas (Lopes et al., 2007). Já o valor médio de turbidez foi maior para os licores da safra de 2017, 65,81 $( \pm 4,03) \%$ do que na safra de 2018, $55,76( \pm 2,78) \%$. A eficiência na filtração das infusões, bem como a dissolução do açúcar no preparo do xarope pode ter contribuído para as variações deste parâmetro.

\section{CONSIDERAÇÕES FINAIS (ou Conclusão)}

Para as duas safras de Jambolão, os resultados na produção de licores utilizando essa matéria-prima exprimem a importância desta como fonte de fitoquímicos e sua capacidade antioxidante. A escassez de informações a respeito da aplicação tecnológica da matéria-prima, mostra interessante que maiores estudos sejam realizados, de modo a haver o beneficiamento e redução do desperdício da fruta. 


\section{REFERÊNCIAS}

ARAÚJO, A. L. M. 2014. Polpa de Jambolão (Syzygium cumini) Desidratada por Liofilização e Secagem em Leito de Jorro: Caracterização Físico-Química e Funcional e Impacto da Secagem. Universidade Estadual do Rio Grande do Norte. Dissertação.

BRANDÃO, T. S. O. et al. 2011. Changes in enzymes, phenolic compounds, tannins, and vitamin $\mathrm{C}$ in various stages of jambolan (Syzygium cumini Lamark) development. Ciência e Tecnologia de Alimento, p. 849-855.

GAMÉZ-MEZA, N. et al. 1999. Antioxidant activity in soybean oil of extracts from Thompson grape bagasse. Journal of the American Oil Chemists' Society, 76 (12), p. 14451447.

GEOCZE, A.C. 2007. Influência da Preparação do Licor de Jabuticaba (Myrciaria jaboticaba Vell berg) no Teor de Compostos Fenólicos. Universidade federal de Minas gerais. Trabalho de Conclusão de Curso.

GEORGÉ, S. et al. 2005. Rapid determination of polyphenols and vitamin C in plant-derived products. Journal of Agricultural and Food Chemistry, 53 (5), p. 1370-1373.

GLORIES, Y. 1984. La couleur des vins rouges. 2ème partie mesure, origine et interpretation. Connaissance de la Vigne et du Vin, v. 18, p. 253-271, 1984.

INSTITUTO ADOLFO LUTZ. 2008. Normas Analíticas do Instituto Adolfo Lutz. v. 4: Métodos químicos e físicos para análise de alimentos. 3. ed. São Paulo: IMESP.

JEONG, S. M. et al. 2004a. Effect of seed roasting conditions on the antioxidant activity of defatted sesame meal extracts. Journal of Food Science, v. 69, p. 377-381.

JEONG, S. M. et al. 2004b. Effect of heat treatment on antioxidant activity of citrus peels. Journal of Agricultural and Food Chemistry, v. 52, p. 3389-3393.

LOPES, T. J. et al. 2007. Antocianinas: uma breve revisão das características estruturais e da estabilidade. Revista Brasileira Agrociência, 13 (3), p. 291-297.

LUZIA, D. M. M.; JORGE, N. 2009. Composição centesimal, potencial antioxidante e perfil dos ácidos graxos de sementes de jambolão (Syzygium cumini L.). Revista Ciência Agronômica, 40 (2), p. 219-223.

MARGRAF, T. et al. 2015. Comparison between Folin-Ciocalteu and Prussian Blue Assays to Estimate The Total Phenolic Content of Juices and Teas Using 96-Well Microplates. Journal of Food Science, 80 (11).

OLIVEIRA, L. M.; BRUNO, R. L. A.; MENEGHELLO, G. E. 2015. Qualidade Fisiológica de Sementes de Syzygium cumini L. Durante o Armazenamento. Ciência Florestal, 25 (4), p. 921-931.

REED, B.J.; HENDRIX Jr., C.M.; HENDRIX, D.L. 1986. Quality Control for Citrus Processing Plants. Florida: Intercit, v. 1.

SINGLETON, V. L.; ROSSI, J. A. 1965. Colorimetry of total phenolics with phosphomolybdic- phosphotungstic acid reagents. American Journal of Enology and Viticulture, v. 16, p. 144- 158.

SOARES, J. C. Aproveitamento Alimentar de Jambolão. 211 f. 2015. Dissertação (Mestrado em Ciência e Tecnologia de Alimentos) - Programa de Pós-Graduação em Ciência e Tecnologia de Alimentos, Universidade Federal de Goiás, Goiânia (GO), 2015.

VIEIRA, V. B. et al. 2010. Produção, Caracterização e Aceitabilidade de Licor de Camucamu (Myrciaria dúbia (h.b.k.) mcvaugh). Alim. Nutr., 21 (4), p. 519-522. 